Chapter 6

\title{
Oxidation and Antioxidants in Fish and Meat from Farm to Fork
}

\author{
Sabine Sampels \\ Additional information is available at the end of the chapter \\ http://dx.doi.org/10.5772/53169
}

\section{Introduction}

Both in meat and especially in fish there is a high risk of quality loss due to oxidation [1, 2]. Lipid oxidation in meat and fish-products leads to rancid taste and off flavor and development of many different substances from which some have even adverse effects to human health e.g. [3]. Oxidation limits storage time and thereby also affects marketing and distribution of both fish and meat products. Especially fish, being rich in n-3 polyunsaturated fatty acids (PUFA) is susceptible to peroxidation of PUFA resulting in restriction of storage and processing possibilities [4]. Furthermore, peroxidative products, particularly aldehydes, can react with specific amino acids to form carbonyls [5] and protein aggregates [6], causing additional nutritional losses. In red meat and also in red fish like salmon oxidation will not only deteriorate the lipids, but also the color $[7,8]$ and thereby affect visual consumer acceptability.

The addition of antioxidants is therefore necessary to increase storage stability, sensory quality and nutritional value of animal products $[9,10]$. Due to the positive health effects of long chain n-3 PUFA, there is an increased interest to produce fish and meat products rich in n-3 PUFA [11]. Increasing the amount of easily oxidized PUFA in animal products however will also require a higher content of antioxidants in the end-product to protect the nutritional valuable fatty acids (FA). The importance of a well-balanced combination of PUFA and antioxidants, both for product stability and human nutrition, was also emphasized by [12]. Beside the traditionally used antioxidants in meat and fish also a wide variation of herbs, spices and fruits are used more and more as additives with antioxidative capacity [13-17]. In the recent years a lot of research has been carried out evaluating these natural substances as antioxidative additives in food products leading to novel combinations of antioxidants and the development of novel food products [17-20]. The high antioxidant capacity of these plant parts is particularly due to their content of different phenols, anthocyanins and ascorbic acid, which can act as radical scavengers [21]. 
In addition to their antioxidative capacity, many of this natural substances have positive effects in the human body and documented health benefits and are therefore highly appreciated food additives [22-27]. So a combination of foods rich in omega 3 PUFA and plant substances rich in phenols and anthocyanins might result in nutritionally very valuable novel food products. These products could play and important role in the prevention of specific chronic-health problems beside dietary supplements where PUFA, probiotics and superfruits are achieving particular interest in the recent time [23, 28]. Finally nutritionally dense meals may be of interest and importance for people with particularly high nutritional demands, e.g. suffering from malnutrition [29].

For animal foods there are always two possible ways to include antioxidants: Via the feed or post mortem during the processing. Depending on the type of antioxidant, the one or the other way will be more effective. In general fat soluble antioxidants like tocopherol are more effective when present in the feed, while water soluble ones like vitamin $C$ are more effective when added during processing [30,31]. In addition there are synergistic effects between different antioxidants as for example shown for tocopherol and ascorbic acid [32] so a good combination of all available tools might be able to boost antioxidative protection for certain products.

The present chapter will give an overview of the main used and tested antioxidants, synergistic effects and the possible increased nutritional value. Feeding effects as well as a variation of processing and preserving methods for animal products from both very traditional and most recent techniques will be presented and their influence on oxidative stability will be elucidated.

\section{General effects of lipid oxidation in meat and fish}

Lipid oxidation is omnipresent in meat and fish and their products. Especially in products with a high amount of unsaturated FA, oxidation leads to rancidity, off-flavour and taste and to the formulation of toxic substances $[2,33,34]$. In the food industry a great deal of research and attention is spend on the on-going oxidative processes. The main aim is always to protect the raw material and the products as good as possible from oxidation through the whole process and during storage.

\subsection{Short introduction to lipids}

In order to get a whole picture about lipid oxidation, it is important to know some basics about lipids and FA. FA consist of carbon chains with a methyl $\left(\mathrm{CH}_{3}\right)$ group at one end and a carboxyl $(\mathrm{COOH})$ group at the other. The $\mathrm{C}$ atoms in the chain can either be saturated or unsaturated meaning they form double bonds between each other. The FA which do not have double bonds are called saturated FA (SFA), those having one double bond are called monounsaturated FA (MUFA) and those with two or more double bonds are called polyunsaturated FA (PUFA) (Fig. 1). The FA are generally named in the scheme $\mathrm{X}: \mathrm{Y} \mathrm{n}-\mathrm{Z}$ where $\mathrm{X}$ is 
the number of carbon atoms in the chain, $\mathrm{Y}$ the number of double bonds and $\mathrm{z}$ the number of the last carbon atom with a double bond counted from the methyl end (see Fig. 1).



Figure 1. Linolenic acid, 18:3 n-3

The $\mathrm{n}$ stands in spoken language for omega so a FA with the last double bond at the third carbon atom from the methyl end is an omega 3 FA while the one with the last double bond at the sixth carbon atom from the methyl group is an omega 6 FA and so on. A very good in depth review about the classification and chemistry of FA and also about their biological functions has been done by $[35,36]$.

\subsection{Reactivity of lipids to oxidation}

The reactivity of unsaturated FA increases with their chain length and number of double bounds $[37,38]$. Beside the number of double bonds also the placing of the double bonds and the form of the FA determine their oxidative reactivity. In general the n-3 FA are more prone to oxidation than the n-6 and those are more prone to oxidation than the n-9 FA [38].

In animal tissues the lipids are usually divided into two main classes: polar lipids (PL) and neutral lipids (NL). NL consist mainly of triacylglycerols (TAG) which are three FA bound to a glycerol molecule, and minor amounts of mono- and diacylglycerols, whereas PL include mainly phospholipids which are diacylglycerols including a phosphatic acid derivate [39]. TAG serve mainly as an energy source, whereas phospholipids are mainly constituents of the cell and organelle membranes being essential for their functionality and fluidity [39-41]. Phospholipids are in general more unsaturated due to their functionality and therefore also more prone to oxidation. In addition free FA (FFA) can occur in raw or processed tissues due to enzymatic breakdown of acylglycerols or phospholipids. The reactivity to oxidation is in general TAG>phospholipids $>$ FFA.

The complicated thing about oxidation is that once it started a cascade of reactions will occur with each new molecule increasing the reaction speed and variability (Fig. 2). The kinet- 
ics of oxidation in meat and meat products are described by [38] and [42]. Oxidation leads to the formation of lipid radicals (L.) that react further to lipid peroxides (LOO) and hydroperoxides (LOOH). Auto oxidation in meat and fish can be initiated by light, heat, presence of metal ions and radicals. Very low concentrations of radicals are needed to start the reaction. Once initiated, oxidation propagates in a chain reaction (steps 2-6). In the termination reactions, lipid peroxides (LOO) will react freely, forming a wide range of more stable products including aldehydes, alkanes and conjugated diens.

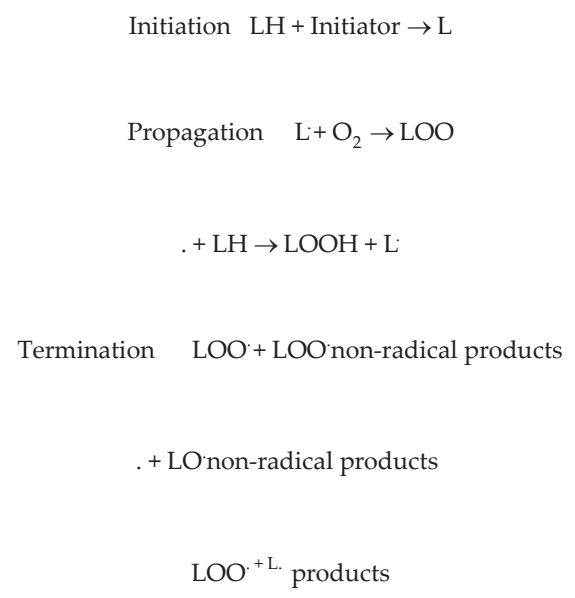

In meat and muscle there are different possibilities to measure the degree of oxidation. The most used ones are listed very briefly here to facilitate the understanding of oxidation parameters used in this chapter:

- The peroxide value: determines the amount of hydroperoxides, which are among the primary products. However, as the peroxides are not stable and react further the results have to be evaluated carefully as, with on-going oxidation the peroxides first increase and reach a maximum but after a while the reaction speed towards secondary oxidation products is faster and the peroxide value decreases again [43].

- TBARS: Another very frequently method is the measurement of thiobarbituric reactive substances (TBARS). Thiobarbituricacid (TBA) reacts with malondialdehyd a secondary oxidation product from PUFA with 3 or more double bonds to a pink complex that can be measured at $532 \mathrm{~nm}$. However the problem with that method is, that other substances also form coloured complexes with TBA and might result in wrong estimation of the oxidation status [44].

- Iodine value: A very traditional method which is still used sometimes to measure the iodine value as a number for the amount of lipid double bonds and the decrease of that number over time as a sign for oxidation. 
- Volatile lipid oxidation products by Headspace GC-MS: During the last decade also more advanced methods have been used more and more for evaluation of oxidation. Content of Hexanal and other volatiles has been shown to give a quite good picture of oxidation status and mechanisms [45,46]. However as these measurement are quite time consuming and expensive they are still not used routinely.

- Free fatty acids: The amount of free FA (FFA) is actually a value for lipolysis. But as the FFA are oxidised faster than bound FA, they can be regarded as a measurement for increased oxidative reactivity of the muscle or product.

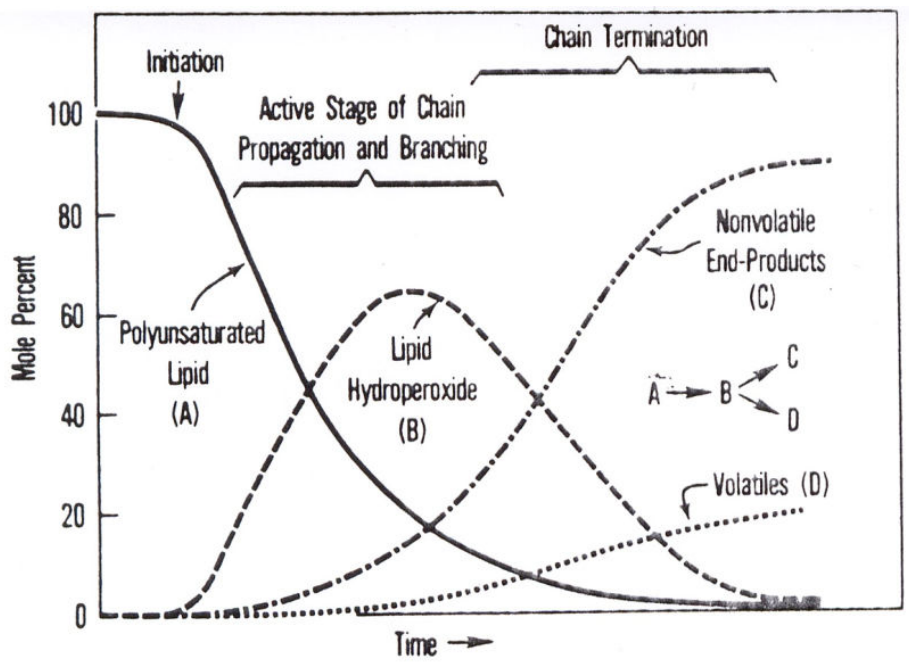

Figure 2. Hypothetical autoxidation of a polyunsaturated lipid as a function of time [47]

\section{Antioxidants in feeds}

Antioxidants can be introduced into the muscle by different means. Coming first in the natural chain from farm to fork would be to add the antioxidants via the feed. Also in the feed antioxidants are needed, to stabilize the lipids in the feed during storage, especially true is that for fish feed with high contents of PUFA.

The main used antioxidant in feeds is the fat soluble Vitamin E, normally added in the form of tocopherol acetate. Vitamin $\mathrm{E}$ is a generic name for all substances that have the biological function of $\alpha$-tocopherol. These include the tocopherols with a saturated phytyl side-chain, (Fig. 3) and tocotrienols with an unsaturated isoprenoid side-chain, substituted to a chroman head. The different forms of tocopherols and tocotrienols are specified by the use of the Greek letters $\alpha, \beta, \gamma$ and $\delta$, to denote the number and position of methyl groups linked to the chroman head [48]. 


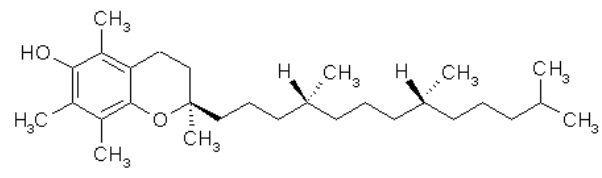

Figure 3. Structure of a-tocopherol

The water soluble vitamin C, ascorbic acid is another antioxidant used in feeds (Fig. 4). However studies have shown that in the live animal tocopherol shows a greater effect, while ascorbic acid works better added post mortem [30, 31].<smiles>O=C1O[C@H]([C@@H](O)CO)C(O)=C1O</smiles>

Figure 4. Structure of ascorbic acid

A third group of natural occurring antioxidants are the also fat soluble carotenoids, the precursors of retinol (vitamin A). They are for example found in corn. Carotenoids are hydrocarbons built from eight isoprene bodies (40 C atoms) (Fig. 5). Due to their structure and the conjugated double bonds, both vitamin $\mathrm{E}$ and the carotenoids, are radical scavengers that can build relatively stable radicals. In addition, carotenoids, tocopherols and tocotrienols are quenchers for singlet oxygen.

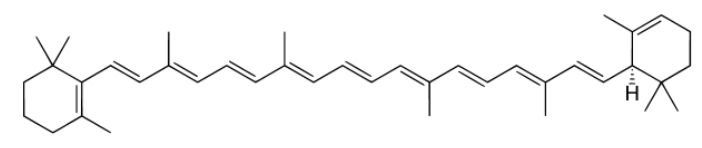

Figure 5. Structure of a-carotene

Carnosine (Fig. 6), a dipeptide, occurring in skeletal muscle which has also been tested as potential antioxidant, however added post mortem [49]. For example [30] suggested using a combination of feed additives and post mortem added antioxidants as for example a feed supplementation with a-tocopheryl acetate and post mortem applied carnosine.<smiles>NCCC(=O)NC(Cc1c[nH]cn1)C(=O)O</smiles>

Figure 6. Structure of carnosine 
Squalene is triterpene (30 C atoms) (Fig.7) that is present in plants and animal tissues as a key intermediate in the biosynthetic pathway to steroids. It has similar to the carotenoids conjugated double bonds and can hence build stable radicals and has been investigated as possible antioxidant [50]. Significant amounts of squalene in plant sources are detected in e.g. olive oil, wheat germ oil, bran oil and yeast [51] as well as in Amaranthus grain and Ecchium plants [52].

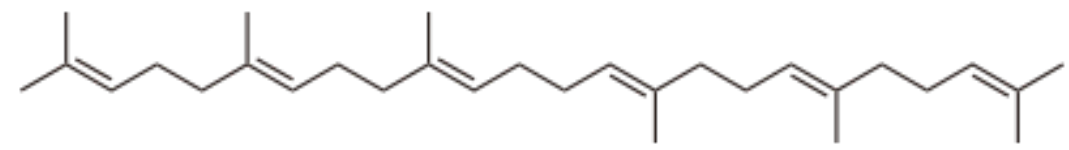

Figure 7. Structure of squalene

As mentioned before, there is also a growing interest to use novel sources of natural antioxidants for feeds, as for example from diverse vegetables [53,54] or spices [55] or from more exotic sources as algae and lichen [56,57]. [56] showed for example that feeding chicken with microalgae did not only increase muscle content of the long chain omega 3 FA docosahexaenoic acid, but also increased content of carotenoids and squalene. [58] supplemented pigs with cranberry powder and found both pro- and anti-oxidative effects, most possibly depending on muscle origin and later processing.

Moreover, there are also always interactions between different nutrients [59-61], which have to be taken into consideration when planning how to achieve antioxidative protection of animal foods. For example did high dietary lipid increase also muscle astaxanthin accumulation in salmon (Salmo salar) [60]. Astaxanthin is a carotenoid that gives the pink colour to salmon muscle but can also act as an antioxidant. In another study [48] showed that dietary intake of sesamin increased uptake of $\alpha$-tocopherol in rats, which suggests that it is possible to increase the bioavailability of antioxidants through feed composition. However, if this mechanism is also valid for fish and other mammals, remains to be investigated.

Concerning the oxidation occurring in the feeds during storage [62] showed that ascorbic acid could protect vitamin E from oxidation in the diet for hybrid tilapia.

Also for the nutritional status of the animals the dietary added antioxidants are of importance. [63] was able to increase the survival of juvenile angelfish (Pterophylum scalare) with a combination of supplemented tocopherol and ascorbic acid in comparison to only tocopherol in the feed. Low dietary vitamin $C$ content has shown to increase requirement of vitamin $\mathrm{E}$ in juvenile salmon [64], suggesting that the deficiency of one antioxidant will lead to the increased use of the available ones. However, bioavailability, efficiency and interactions with other substances might vary between different species as summarized by [63]. 


\section{Antioxidants added during processing/effect of processing techniques}

\subsection{Oxidation factors in muscle and product}

\subsubsection{Metals}

Oils and animal foods always contain a small amount of metals which are too difficult to remove, as for example iron from myoglobin, hemoglobin and the iron storage protein ferritin, or copper, zinc and heavy metals that are present in enzymes and metalloproteins [40, 65]. Another source of metals in animal food products are the machines used during processing, from which minor amounts of iron can get into the products either by abrasion or due to acidic dissolving of metals from the surface. A third source can be migration of metals from the packaging. These metals are present in so low amounts that they do not have a physiological effect; however, they can have pro oxidative effects [66].

\subsubsection{Salt}

Salt is used for the preservation of meat and fish. Due to its water activity lowering effect and the withdrawl of free water, salt decreases the solubility of oxygen as well as the activity of enzymes and bacteria. In addition chloride ions are also toxic to certain microorganisms. However it is also a pro-oxidant [67].

\subsubsection{Oxygen, light and temperature}

The more and longer a product is exposed to light and oxygen, the higher is the risk and speed of oxidation. When fish or meat is cut into pieces or minced, the surface is substantially increased and thereby the accessibility for oxygen. As light and increased temperature enhance oxidation $[40,68]$, during processing temperature and the processing time should be kept as low and short as possible respectively.

\subsection{Different preservation and processing techniques:}

Various processes including cooling, salting, drying, smoking and heating have been used for a long time to preserve meat and fish and to obtain a variety of products with characteristic organoleptic characteristic $[2,69,70]$ Processing is a primarily way to preserve meat, but also adds to its value. However, different processing steps can also negatively affect meat quality, and change for example lipid quality traits. Heating of meat and meat products e.g. hot smoking, can disrupt the cell membranes and promote lipid oxidation [71], which affects the nutritional and sensory properties of the meat product. Use of antioxidants during processing or alternative more gentle processing methods can reduce these negative effects.

\subsubsection{Chilling or cooling}

Fresh meat is sold chilled at a temperature of about $+4^{\circ} \mathrm{C}$. Preservation of meat quality is an important criterion for its shelf life, since raw, chilled meat has traditionally been a perishable product $[1,72]$. In order to prolong the chilled storage time advanced packing techniques or various additives are used in addition, which will be described in more detail in the following. 
Fresh fish is usually transported and sold on flaked ice, keeping the temperature slightly above $0^{\circ} \mathrm{C}$; more recently also ice slurries have been used $[2,73]$. To make these ice slurries even more effective different additives to fish as well as to the ice slurry have been used. Examples are natural antioxidants, ozone or organic acid mixtures. [73] evaluated the effect of organic acids mixed into the ice slurry on lipid oxidation and found slightly decreased oxidation. On the other hand [74] showed a significant decrease of lipid oxidation when fish was stored in ice made with water extracts from rosemary or oregano. [2] gives a good review on different additives to slurry ice and summarizes among others that addition of ozone declined microbial spoilage and did not increase oxidation. Addition of antioxidants directly to the fish will be discussed further on in this chapter.

\subsubsection{Super chilling or deep chilling}

Super chilling or deep chilling means in general to chill the products to a temperature close to or just below the initial freezing point, which is for the most food products between -0.5 and $-2.8{ }^{\circ} \mathrm{C}$ (reviewed by [75]). In regard to lipid oxidation it is important that there are no ice crystals formed, as they can destroy organelle membranes and thereby release enzymes and enhance oxidation potential [76]. This technique is used for example for deer meat exported from New Zealand to Europe. The international trading demands new techniques to provide longer storage times. Due to long transport distances and high export quantities, deer meat from New Zealand is stored in vacuum packages and deep chilled to $-1.5^{\circ} \mathrm{C}$, and can be considered as fresh meat up to 14 weeks after slaughter [77]. The low temperatures, combined with vacuum, retard bacterial growth, lipid oxidation and color deterioration. There is not done much work on lipid oxidation during deep chilling, however [75] suggested that the improved shelf life and quality reported from deep chilled foods is also indirect resulted by a reduction of lipid deterioration.

Also in fish and seafood deep chilling has been applied successfully and shown to retard microbial growth and extend shelf life of for example prawn (Penaeus japonicas) [78] salmon and $\operatorname{cod}($ Gadus morhua) $[79,80]$, however without investigating the effects on lipid oxidation.

\subsubsection{Freezing}

Frozen storage has since long been a method considered sufficient to preserve meat over longer time periods [81], however freezing can also negatively influence structural and chemical properties of meat, e.g. increase content of FFA and lipid oxidation products [82, 83]. [83] reviews some aspects related to lipid oxidation during and after freezing and describes the amount of unfrozen water as one important factor for primary oxidation. The amount of unfrozen water depends on the freezing temperature and in line with that an optimum freezing temperature for meats of $-40^{\circ} \mathrm{C}$ has been suggested by [84]. At this temperature only a minor fraction of the water is unfrozen. In agreement with that [85] showed a significant increase of lipid oxidation products in pork stored at $-18^{\circ} \mathrm{C}$. Besides the temperature, the formation of ice crystals during freezing is a critical point [76] and the larger ice crystals are formed the higher is the risk of membrane disruption and increased oxidation. 
An important element to avoid increased oxidation after thawing should therefore be the formation of small ice crystals during freezing. The faster and more homogeneous the freezing happens, the smaller and more uniform the formed ice crystals will be [86]. Some recent developed fast freezing techniques suitable for muscle foods are high pressure freezing, pressure shift freezing, cryogenic freezing and the already since longer time used air-blast freezing [86, 87]. [87] showed that substantial smaller ice crystals were formed in Norway Lobster (Nephrops norvegicus) when pressure shift freezing was used compared to air blast freezing. However, most of the papers, studying effects of freezing, evaluate only texture, drip loss and sensory, therefore not much is known about the effects of different techniques on lipid oxidation.

Once frozen, it is important for the maintenance of the small ice crystals that a stable temperature is kept, as thawing and refreezing as well as temperature fluctuations lead to formation of bigger ice crystals [861895]. Beside different techniques of the freezing itself, the injection or dipping of antifreeze proteins for both meat and fish has shown some success to force the formation of preferably small ice crystals (reviewed by [86]). Addition of antifreeze proteins has also shown to inhibit recrystallization of small ice crystals into bigger ones (reviewed by [86]).

\subsubsection{Salting and curing}

Meat curing and salting of fish are among the oldest preservation techniques man has used [88]. As described above salt has pro-oxidative effects. A demonstration of the pro-oxidative effect of salt in muscle foods can be found in [89]. During the process of meat curing with salt, nitrite is usually added to keep the nice pink color of the meat. The nitrite exchanges the oxygen ligand in the oxymyoglobin (Fig. 8), which is responsible for the bright red colour of fresh meat, and builds another very stable pink colored complex, the nitrosylmyoglobin [88]. [90] showed in addition an antioxidative effect of nitrite in meat and discussed different possible reaction mechanisms.

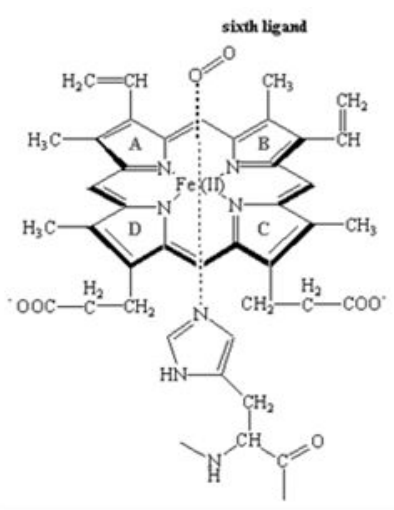

Figure 8. Structure of oxymyoglobine 
Salting of fish is very commonly used traditional preservation process [91]. In many cases as for example in the traditional salted herring, salting and ripening takes a quite long ripening time. However [91] showed also that only a modest increase of peroxide values occurred during the ripening time. However as the FFA increased substantially in the brine and as peroxide values show only primary oxidation products substantial oxidation might have happened undetected. An indicator for oxidative stress during the ripening process is the drop of $\alpha$ - tocopherol to approximately $50 \%$ after 371 days in that study. However as also pointed out in the section about drying in this chapter, part of the oxidation products might be part of the desired characteristic organoleptic properties.

[66] investigated the effect of trace metals in the used salt during the salting of cod, showing a significant increase of TBARS with increasing copper concentration and during the salting time. Various attempts have been made to study oxidation during various salting processes and to find ways to inhibit or decrease lipid oxidation. [92] showed that salting initially protected chub mackerel (Scomber japonicus) from oxidation, however after 12 days of storage TBARS values were significantly higher in salted non-smoked fish compared to unsalted non-smoked fish. However, [93] showed that partial replacement of $\mathrm{NaCl}$ with $\mathrm{KCl}$ decreased lipid oxidation in salted mackerel as well as addition of ascorbic acid to brine solution. [94] found that EDTA prevented copper induced oxidation in salt brined cod, while added citrate enhanced oxidation and ascorbate had no effect in that study.

Besides the use of salting for preservation, fish is sometimes mildly salted to improve sensory characteristics and water holding capacity, where contents of only $0.1-0.3 \%$ can give significantly improved water holding capacity [17] but also resulted in increased oxidation levels in herring (Clupea harengus).

\subsubsection{Drying}

Dry curing and drying of meat also involve pro-oxidative factors, as there are: long exposure to air, dehydration and absence of nitrite [95]. Enzymatic activity can lead to high amounts of FFA, which are more prone to oxidation than TAG [34,88]. In products such as dry-cured ham or dry-cured salami, a certain amount of volatiles, lipid oxidation compounds and lipolysis products is desired since they are responsible for the particular taste of these products [4,96]. In line with this [97] showed that the traditional drying process of reindeer meat led to significantly increased oxidation parameters compared to the raw meat or smoked reindeer meat. On the other hand, excessive amounts of oxidation products result in off-flavors and rancid taste [98] and should hence be avoided.

[70] reviewed that in dry cured hams the lipases stay active for several month and hence can produce high amounts of FFA in the tissue. [99] confirmed this in their experiment showing a constant increase of FFA during 24 month of aging of dry cured hams. However TBA values did not increase significantly during that time. Evaluating how to avoid excessive oxidation in dry cured Parma hams, [100] showed that dietary tocopherol could decrease oxidation even in hams with an increased proportion of unsaturated FA. 
Also various dried fish products exist, however most work done on dried fish products deals with microbial spoilage or sensory aspects as for example in cod [101, 102] and only few works also evaluate lipid oxidation. But [103] compared different drying methods for dried milkfish (Chanos chanos), a traditional Taiwanese product. In their study cold air drying resulted in significant lower TBA values than the traditional sun drying or hot air drying. They conclude that both light and temperature were important factors which induce increased oxidation. These results agreed with [104] who evaluated different drying methods on dried yellow corvenia (Pseudosciaena manchurica) and found higer oxidation in products made by the traditional sun drying process. Other works found on dried fish $[66,94]$ investigated heavily salted cod, and are hence discussed in the previous section about salt.

\subsubsection{Smoking}

Smoking is another traditional method to preserve meat and fish and create new products. [88] described the antioxidative activity of some of the smokes components. The various techniques and the types of wood used lead to the characteristic taste of the final product [105]. However as hot or warm smoking also includes increased temperature over a longer period and the meat parts are usually salted before smoking, also always some oxidation is initiated. In line with that effects are in general more complex, considering the various proand antioxidative aspects of this way of processing. For example [92] showed that smoking initially increased oxidation in chub mackerel (Scomber japonicus) but that it had lipid oxidation decreasing effects during storage, leading to lower TBARS values in the smoked fish compared to the unsalted non-smoked fish after 6 days.

In addition the smoke contains also substances that have been associated adverse health effects [106]. Therefore different processing methods as for example the use of liquid smoke have been investigated. [107] showed that a combination of liquid and traditional smoke were more effective inhibiting lipid oxidation in bacon than traditional smoke alone. These results were ascribed to a possible higher content of phenols in the samples processed with the combined smoking procedure. Contradictory [108] showed that traditional smoke resulted in lower TBA values compared to the use of liquid smoke in smoked beef tongue after 5-30 days storage. [109] compared traditional cold smoking and electrostatic smoking of salmon and concluded that electrostatically smoked fillets had a higher loss of lipids, but were less oxidized than traditional smoked fillets.

\subsubsection{Packaging}

From an oxidation point of view, packing should be tight and compact so that the surface and oxygen access are minimized. However this will not always meet the customers' expectations of product presentation, so naturally compromises have to be made. Packaging systems and technologies have developed rapidly during the last decades [1]. Both in meat and fish the principal function is to limit bacterial spoilage and growth. In red meats also the preservation of a bright red color is important, which is an indicator of freshness for the consumers [7]. This will be reached for example by keeping a high percentage of oxygen in a modified atmosphere package (MAP), while most bacteria are inhibited by an increased 
concentration of $\mathrm{CO}_{2}$ at the same time. For the different types of meat and fish the perfect gas mixture differs. A good overview is given by [110]. In fat fish due to the high oxidation risk a gas mixture without oxygen is generally recommended. [49] tried to use various antioxidants combined with modified atmosphere and showed increased lipid and color stability when a combination of rosemary and ascorbic acid was used in MAP.

Examples for the application of vacuum packing technique are given by [111] for fish burgers and by [80] for salmon fillets. Unfortunately these studies have not investigated oxidation in normal versus vacuum packing. However [112] investigated the effect of different storage conditions on oxidation in burgers made from rabbit meat and found decreased oxidation when vacuum packing was used.

\subsubsection{Other preservation methods (irradiation)}

Low dose irradiation is a very effective method to kill many bacteria including Salmonella and Escherichia coli, but it is also known to generate hydroxyl radicals and could hence lead to increased oxidation in meat and fish products [113]. [114] evaluated the effect of low dose irradiation up to $9.43 \mathrm{kGy}$ on different meats (pork, beef, lamb and turkey) and found only low dependency between lipid oxidation values and the irradiation dose. However slightly higher values of malondialdehyd were found in turkey breast with the highest dose compared to the other meats at the same dose. [115] found increased oxidation values in pacu (Piaractus mesopotamicus) fish after irradiation. Nevertheless, in the same experiment the researchers showed addition of antioxidants $\alpha$-tocopherol, BHT or rosemary extract could inhibit the oxidation accelerated by irradiation.

\subsubsection{Canned meat and fish products}

In canned fish the major part of oxidation seemed to occur due to the heating step before and during sterilization [116, 117]. [117] reviewed that also the storage conditions (time and temperature) before the actually canning do have a significant influence on the final content of oxidation products. The longer the storage time and the higher the storage temperature the more oxidation and lipolysis will take place and the higher the content of easily oxidable FFA will be. Beside these factors also the filling media seemed to have a significant impact [117]. [116] showed a significant increase of TBA values in silver carp canned with brine, sunflower oil and soybean oil while olive oil seemed not to enhance oxidation. On the other hand [117] evaluated the effect of natural antioxidants from the canning oil on canned tuna and found protective effects against lipid oxidation from extra virgin olive oil rich in phenols and also partly from soybean oil rich in tocopherols. Highest oxidation was found in tuna canned in brine in that experiment. [117] ascribed that to a possible accumulation of the PUFA at the oil-water surface. In general the results show that even added antioxidants like spices or other plant antioxidants could have a positive effect against oxidation in canned fish products. However, to our knowledge the effect of the addition of antioxidants or the effect of spices present in the brine has not been investigated yet. 
In canned meat products the situation is expected to be similar as in fish, but not as much research as on fish products concerning oxidation has been executed. This might be due to the fact that there are more canned fish products on the market and that fish is known to have higher susceptibility to oxidation due to its higher content of PUFA. However, in one of the few more recent studies [118] investigated the importance of the raw product composition and found lowest oxidation in the product with lowest fat content.

\subsection{Ready to eat and fast food products}

There is a wide variety of ready to eat products from meat and fish available on the market, such as sausages, meat- or fish balls, paté's and many more. As these products often include minced or grinded meat and several other ingredients beside the raw muscle as well as they require several processing steps, all of these will have an influence on the oxidation behavior. On the other hand this creates a great chance to add antioxidants or to optimize processing techniques and packaging towards the lowest possible oxidation status of the final product. In general it can be said that also in this case the fish products will be the ones which are more prone to oxidation due to their more unsaturated FA composition. However also other aspects play a role as for example [119] found comparable cholesterol oxide values in one of three pork paté's as in a cod paté, while two other pork patés and a tested salmon and anchovy paté had lower values.

Antioxidants additives in fast food products are for example rosemary extract showing an antioxidative effect in mackerel burgers [111] and or as a more novel ingredient yerba mate extracts, which enhanced lipid stability in beef hamburgers [120]. [121] showed protective effects of oregano and thyme oil in ready to eat squid rings and [122] showed antioxidative effects of various herbs in pork patties.

But also processing methods or packaging can be used to increase oxidative stability. For instance [111] used vacuum packing in addition with the applied antioxidants in the mackerel burgers, while [123] evaluated a combination of irradiation and different packing environments to increase shelf life in pork patties.

Sausages are very favorite and omnipresent meat products around the world. A wide variety of categories such as raw, cooked, dry fermented, cooked smoked, raw smoked or precooked sausages exist. Through the addition of especially spices the oxidation in these products can efficiently be decreased [124] for example used Spanish paprika and garlic or a mixture of nitrite, nitrate and ascorbic acid in chorizo type sausages. They concluded that paprika showed a potent antioxidant capacity in this type of product and that a mixture of $3 \%$ paprika and $1 \%$ garlic had similar antioxidative effects as a traditional used curing mixture of nitrite, nitrate and ascorbic acid. [125] tested rosemary as spice and natural antioxidant in fermented goat sausages and found lower oxidation and increased values of overall sensory. Adding Palatase M. (from Rhizomucor miehei) to dry fermented sausages in order to improve sensory aspects, resulted in increased FFA content, however no correlation with higher TBARS could be found by [126]. On the other hand, the authors found an increased amount of volatile compounds which could indicate an increased oxidation due to the added enzyme. 


\section{Antioxidants in meat and fish products}

Antioxidants delay or inhibit the process of oxidation, even when present in low concentrations [127]. Some antioxidants function as radical scavengers or peroxide decomposers, while others quench singlet oxygen, remove catalytic metal ions or oxygen, or inhibit enzymes. The cellular antioxidants can be classed as low molecular substances and enzymes that are either water-soluble or fat-soluble.

\subsection{Spices and herbs}

It is well known that phenolic compounds from spices and herbs have an antioxidative potential due to their possibility to act as a radical scavengers [128, 129]. A short review and a list of some polyphenols with their respective antioxidant activity can be found in [129]. Various spices have hence been tested in a wide range of products from sausages over meatballs to fish fillets and fish oil $[124,125,130,131]$. [16] showed that $1.5 \%$ sage added to meatballs decreased oxidation and limited undesirable changes in the composition.

The advantage in the use of spices and herbs is that they are natural and in case of various products often are anyway included in the spicing or that they blend in to the desired taste of the final product. Consumers appreciate having natural antioxidants in their products over synthetic ones. However a problem might be if the taste of the used spice/herb does not fit with the product or gives a too strong side taste. For example [111] found that addition of $0.4 \%$ rosemary gave improved shelf life of fish burgers with an acceptable taste for the consumers, while $0.8 \%$ of rosemary gave a too intense taste.

[132] compared the antioxidative activities of 22 commonly used herbs and spices added in different amounts to pork meat and found highest antioxidant capacity in sansho, ginger and sage. Furthermore also addition of rosemary, thyme, oregano and allspice resulted in up to $64 \%$ inhibition of lipid oxidation.

\subsection{Fruits and berries}

The high antioxidant capacity of berries is particularly due to their content of different phenols, anthocyanins and ascorbic acid [21]. Besides health benefits related to their natural antioxidants, colour attributes of berries are also of interest in food processing, as colour plays a vital role to the acceptability of foods. A wide range of various fruits and berries has shown antioxidant capacity as for example cranberries, elderberries, black currant and many more [133, 134].

For example, grape seed extracts were used to inhibit lipid oxidation in muscle from chicken, beef and pork [14] as well as in turkey meat [135] and polyphenols extracted from grape pomance inhibited lipid oxidation in fish muscle [136].

Even more unusual combinations have been tested successfully, as for example the antioxidative effect of various berry concentrates as marinades for herring fillets [17]. Other applications are cranberry juice powder as antioxidant rich feed for pigs [58], cranberry extract as 
additive to separated turkey and ground pork meat [137], grape antioxidant dietary fibre in minced fish [138] or tomatoes in beef patties.

\subsection{Antioxidants from other sources}

Beside spices, herbs and fruits also teas and other possible sources for natural antioxidants have been evaluated.

Among others, tea catechins have been tested and used as antioxidants in various food products. Extracted tea catechins from green tea showed significant potential to inhibit lipid oxidation in red meat, poultry and in fish muscle [139]. Instant green tea has shown to slow down oxidation in frozen mackerel [140].

Chitosan is the deacetylated form of chitin and has been shown to have antibacterial and antifungal properties and has therefore reached some attention as food additive [141]. In its original form it is ineffective as antioxidant, however [141] have shown that as a glucose complex chitosan exhibited both antimicrobial and antioxidative effects in pork salami.

Besides research is constantly searching for new sources of antioxidants as for example tomato seed oil from tomato pomance (industrial tomato waste) [142] or industrial onion waste [54]. These antioxidant rich waste products could be added to the animals feed as successfully shown by [53] where eggs from chicken fed tomato byproducts contained higher amounts of lycopene compared to normal eggs. Or on the other hand extracts from these byproducts could be used as additives directly to the food products as suggested by [143]. Similarly byproducts from wine and olive oil byproducts inhibited oxidation in minced fish and frozen mackerel fillets respectively $[138,144]$. As a more exotic possible additive [145] investigated antioxidant properties of Indian red seaweeds.

\subsection{Synergistic effects and interactions}

As mentioned before, in addition to the antioxidative effect a substance has alone, there are as well always interactions that can influence the bioavailability, the antioxidative effect and mechanisms between the various nutrients.

For example vitamine $\mathrm{C}$ and vitamine $\mathrm{E}$ have been found to interact as antioxidants, tocopheroxy radicals are reduced back to tocopherols by ascorbic acid [32]. As in meat and fish products this mechanisms takes place at the border between lipid and water phase, the radical is removed from the lipid phase and the lipid oxidation process due to that radical is terminated.

[146] describes the function of carotenoids in what he calls antioxidant networks, were carotenoids act together with other antioxidants at interfaces as for example xanthophylls and carotenoids in egg yolks and fish. Similar to the synergistic action of tocopherols and ascorbic acid, the more hydrophilic (iso)flavonoids and their glycosides regenerate the lipophilic carotenoids which are active as radical scavengers in the lipid phase. In another mechanism the more hydrophilic xanthophylls act via the membranes between water/lipid interfaces in synergism with more lipophilic carotenoids. [146] defines concluding two types of conditions how carotenoids function: (i) in "equilibrium" with other antioxidants in thermodynamically controlled 
networks serving as color indicators of good antioxidant status and (ii) as antioxidants active through radical scavenging in networks with kinetically controlled regeneration. Furthermore carotenoids also showed to enhance antioxidant activity of vitamin E [147]. Moreover [109] reported that astaxanthin and tocopherol act via different mechanisms in salmon and hence improve stability against oxidation at different stages of oxidation.

Squalene has been found to protect $\alpha$-tocopherol in oxidation processes [148], probably in a similar way of action than those described for the carotenoid networks.

The use of combined added antioxidant and other preserving techniques has also shown effects as earlier presented in the case of [49] where modified atmosphere packaging was used in combination with antioxidants and where also the combination of two different antioxidants, namely rosemary and ascorbic acid gave the best results. Furthermore [93] showed that a combination of various preservation techniques gave the best results against lipid oxidation in salted mackerel. Combined frozen storage at $-18^{\circ} \mathrm{C}$ in a vacuum package and added ascorbic acid at the same time as $50 \%$ of the $\mathrm{NaCl}$ was replaced by $\mathrm{KCl}$ gave the best results in that study.

On the other hand [94] showed that ascorbate might have pro-oxidative effects due to concentration and depending on the presence or absence of other oxidants. For instance did ascorbate concentrations below 50ppm in combination with $5 \mathrm{ppm}$ copper in the brine prevented formation of TBARS while concentrations above $500 \mathrm{ppm}$ in absence of copper had pro-oxidative effects.

Effects of other nutrients on antioxidant uptake and accumulation were shown by [109] who showed a positive correlation between fat content and tocopherol accumulation and a negative correlation between fat content and content of ascorbic acid in salmon. [149] showed negative effects of high dietary astaxanthin on $\alpha$-tocopherol deposition in rainbow trout (Oncorhynchus mykiss)

There is still much room for novel combinations that might give improved oxidative stability to varying products and hence more research in that field is strongly needed.

\section{Additional value in antioxidant rich foods}

Generally, antioxidants maintain product quality by improving shelf-life, nutritional quality and other aspects related to quality. Meat and fish products have been successfully enhanced with different spices and new food ingredients, to prevent oxidation and increase thereby both nutritional value, storage stability and sensory.

The positive effects of tocopherol and ascorbic acid on human health in their property as vitamins are obvious. But beyond that compounds like polyphenols, carotenoids and catechins have shown to influence human health thanks to various other properties beside their antioxidative capacity. For instance [150] gave a valuable review on antioxidant and antimicrobial effects of various berries and their impact on human health and [151] reviewed the 
anti-inflammatory properties, effects on cancer, diabetes, the immune system, and ocular health of asthaxanthin. [152] reviews the anti-inflammatory, anti-allergic, antimicrobial and cancer-preventive effects of polyphenols, which are mainly due to their antioxidant activity; and describes that polyphenols furthermore can directly bind with signaling molecules involved in inflammatory mechanisms and carcinogenesis and thereby regulate cell activity. In line with that review, [153] gave an overview about the various positive effects of tea catechins on human health, as for example protection against bacterial induced dental caries and antiviral properties.

Examples for the health effects associated with different berries and fruits are numerous: Cranberries are known for their prevention of urinary tract infections [154]. [155] reviews the antioxidative and cardio-protective actions of Chilean blackberries and [156] reviewed the positive effect of grape juice, berries and walnuts on age related diseases. The authors discuss that beside the antioxidative and anti-inflammatory effects, polyphenols as for example antocyanins and proanthocyanidins enhance neuronal communication and neuronal signaling and decreased oxidative and inflammatory stress occurring due to aging.

As already mentioned before, besides inhibiting oxidation, plant substances can also have protective effect against microbial growth. [141] described the combined antioxidative and antimicrobial effects of chitosan as well as $[157,158]$ showed that oregano and cranberry inhibit Heliobacter pylori and Listeria monocytogenes in fish and meat beside their antioxidative capacity. Hence some plants with antioxidant capacity are also protecting from food poisoning.

\section{Outlook/novel foods}

Considering the various properties of natural compounds as polyphenols, carotenoids terpenes and catechins, waste possibilities for the development of novel foods are still unexplored. For example the importance of a balanced combination of PUFA and antioxidants, both for product stability and human nutrition, was outlined by [12]. When increasing the amount of PUFA and especially the proportion of n-3 also increased proportions of antioxidants are needed to keep a good storage stability of fish and meat products and prevent oxidation [12]. Hence, combining fish or meat and various plant products as berries or spices may be interesting from nutritional, sensory and technological points of view.

Beside this nutritionally packed meals high in PUFA, antioxidants and nutritional beneficial substances may be especially important to people with particularly high nutritional demands, for example elderly people who suffer from malnutrition [29]. The plate of novel dishes that could be developed is broad, an example from recent research are fish dishes rich in polyphenols from berries [17]. Furthermore [159] describes the concept of FOSHU (foods for specified health use) and nine novel meat products that have been approved in Japan claiming to have beneficial effects on various aspects of human health. 


\section{Acknowledgements}

This publication was financed through the projects CENAKVA (CZ.1.05/2.1.00/01.0024) and GA JU 047/2010/Z.

\section{Author details}

Sabine Sampels

Faculty of Fisheries and Protection of Waters, South Bohemian Research Center of Aquaculture and Biodiversity of Hydrocenoses, University of South Bohemia in Ceske Budejovice, Czech Republic

\section{References}

[1] Jeremiah, L.E., Packaging alternatives to deliver fresh meats using short- or longterm distribution. Food Research International, 2001. 34(9): p. 749-772.

[2] Medina, I., J.M. Gallardo, and S.P. Aubourg, Quality preservation in chilled and frozen fish products by employment of slurry ice and natural antioxidants. International Journal of Food Science and Technology, 2009. 44(8): p. 1467-1479.

[3] Ames, B.N., M.K. Shigenaga, and T.M. Hagen, Oxidants, Antioxidants, And The Degenerative Diseases Of Aging. Proceedings of the National Academy of Sciences of the United States of America, 1993. 90(17): p. 7915-7922.

[4] Gray, J.I., E.A. Gomaa, and D.J. Buckley, Oxidative Quality and Shelf Life of Meats. Meat Science, 1996. 43(1): p. S111-S123.

[5] Uchida, K. and E.R. Stadtman, Covalent Attachment Of 4-Hydroxynonenal To Glyceraldehyde-3-Phosphate Dehydrogenase - A Possible Involvement Of Intramolecular And Intermolecular Cross-Linking Reaction. Journal of biological Chemistry, 1993. 268(9): p. 6388-6393.

[6] Buttkus, H., Preparation And Properties Of Trout Myosin. Journal of the Fisheries Research Board of Canada, 1966. 23(4): p. 563-573.

[7] Faustman, C. and R.G. Cassens, The biochemical basis for discoloration in fresh meat: a review. Journal of Muscle Foods, 1990. 1: p. 217-243.

[8] Scaife, J.R., et al., Influence of alpha-tocopherol acetate on the short- and long-term storage properties of fillets from Atlantic salmon Salmo salar fed a high lipid diet. Aquaculture Nutrition, 2000. 6(1): p. 65-71. 
[9] Kazimierczak, R., et al., Antioxidant content in black currants from organic and conventional cultivation. Electronic Journal of Polish Agricultural Universities, 2008. 11(2): p. art 28.

[10] Ladikos, D. and V. Lougovois, Lipid Oxidation in Muscle Foods - a Review. Food Chemistry, 1990. 35(4): p. 295-314.

[11] Wood, J.D., et al., Effects of fatty acids on meat quality: a review. Meat Science, 2003. 66(1): p. 21-32.

[12] Kamal-Eldin, A. and J. Pickova, Balance between polyunsaturated fatty acids and antioxidants in nutrition. Lipid Technology: 2008. 20(4) 80-83.

[13] Bhale, S.D., et al., Oregano and rosemary extracts inhibit oxidation of long-chain n-3 fatty acids in menhaden oil. Journal of Food Science, 2007. 72(9): p. C504-C508.

[14] Brannan, R.G. and E. Mah, Grape seed extract inhibits lipid oxidation in muscle from different species during refrigerated and frozen storage and oxidation catalyzed by peroxynitrite and iron/ascorbate in a pyrogallol red model system. Meat Science, 2007. 77(4): p. 540-546.

[15] Haak, L., K. Raes, and S. De Smet, Effect of plant phenolics, tocopherol and ascorbic acid on oxidative stability of pork patties. Journal of the Science of Food and Agriculture, 2009. 89(8): p. 1360-1365.

[16] Karpinska, M., J. Borowski, and M. Danowska-Oziewicz, The use of natural antioxidants in ready-to-serve food. Food Chemistry, 2001. 72(1): p. 5-9.

[17] Sampels, S., et al., Berry Marinades Enhance Oxidative Stability of Herring Fillets. Journal of Agricultural and Food Chemistry, 2010. 58(23): p. 12230-12237.

[18] Coma, V., et al., Edible antimicrobial films based on chitosan matrix. Journal of Food Science, 2002. 67(3): p. 1162-1169.

[19] Perumalla, A.V.S. and N.S. Hettiarachchy, Green tea and grape seed extracts - Potential applications in food safety and quality. Food Research International, 2011. 44(4): p. 827-839.

[20] Girones-Vilaplana, A., et al., A novel beverage rich in antioxidant phenolics: Maqui berry (Aristotelia chilensis) and lemon juice. Lwt-Food Science and Technology, 2012. 47(2): p. 279-286.

[21] Pantelidis, G.E., et al., Antioxidant capacity, phenol, anthocyanin and ascorbic acid contents in raspberries, blackberries, red currants, gooseberries and Cornelian cherries. Food Chemistry, 2007. 102(3): p. 777-783.

[22] Aron, P.M. and J.A. Kennedy, Flavan-3-ols: Nature, occurrence and biological activity. Molecular Nutrition \& Food Research, 2008. 52(1): p. 79-104. 
[23] Giusti, M.M. and R.E. Wrolstad, Acylated anthocyanins from edible sources and their applications in food systems. Biochemical Engineering Journal, 2003. 14(3): p. 217-225.

[24] Hsu, C.L. and G.C. Yen, Phenolic compounds: Evidence for inhibitory effects against obesity and their underlying molecular signaling mechanisms. Molecular Nutrition \& Food Research, 2008. 52(5): p. 624-625.

[25] Karaaslan, M., et al., Phenolic fortification of yogurt using grape and callus extracts. Lwt-Food Science and Technology, 2011. 44(4): p. 1065-1072.

[26] Blando, F., C. Gerardi, and I. Nicoletti, Sour cherry (Prunus cerasus L) anthocyanins as ingredients for functional foods. Journal of Biomedicine and Biotechnology, 2004(5): p. 253-258.

[27] Ghosh, D., Potential role of polyphenol-fortified foods and beverages on vascular health. Agro Food Industry Hi-Tech, 2009. 20(6): p. 25-26.

[28] Runestad, T. Functional Ingredients market overview. 2007 http://www.functionalingredientsmag.com/article/Business-Strategies/-em-functional-ingredients-em-market-overview.aspx [accessed 3.11.2009].

[29] Wilson, M.-M.G. and J.E. Morley, Invited Review: Aging and energy balance. J Appl Physiol, 2003. 95(4): p. 1728-1736.

[30] Morrissey, P.A., et al., Lipid stability in meat and meat products. Meat Science, 1998. 49: p. S73-S86.

[31] Bou, R., et al., Influence of dietary fat source, alpha-tocopherol, and ascorbic acid supplementation on sensory quality of dark chicken meat. Poultry Science, 2001. 80(6): p. 800-807.

[32] Packer, J.E., T.F. Slater, and R.L. Willson, Direct observations of a free redical interaction between vitamin E and vitamin C. Nature, 1979. 278: p. 737-739.

[33] Dobarganes, C. and G. Marquez-Ruiz, Oxidized fats in foods. Current opinion in clinical nutrition and metabolic care, 2003. 6(2): p. 157-163.

[34] Enser, M., What is lipid oxidation? Food Science and Technology-Lebensmittel-Wissenschaft \& Technologie, 1987. 1: p. 151-153.

[35] Tvrzicka, E., et al., Fatty Acids As Biocompounds: Their Role In Human Metabolism, Health And Disease - A Review. Part 1: Classification, Dietary Sources And Biological Functions. Biomedical Papers-Olomouc, 2011. 155(2): p. 117-130.

[36] Kremmyda, L.S., et al., Fatty Acids As Biocompounds: Their Role In Human Metabolism, Health And Disease - A Review. Part 2: Fatty Acid Physiological Roles And Applications In Human Health And Disease. Biomedical Papers-Olomouc, 2011. 155(3): p. 195-218. 
[37] Kubow, S., Routes of formation and toxic consequences of lipid oxidation products in foods. Free Radical Biology and Medicine, 1992. 12(1): p. 63-81.

[38] Cosgrove, J.P., D.F. Church, and W.A. Pryor, The kinetics of the autoxidation of polyunsaturated fatty-acids. Lipids, 1987. 22 (5): p. 299-304.

[39] Henderson, R.J. and D.R. Tocher, The lipid composition and biochemistry ofd freshwater fish. Progress in Lipid Research, 1987. 26: p. 281-347.

[40] Jacobsen, C., et al., Preventing lipid oxidation in seafood, in Improving Seafood Products for the Consumer, T. Borresen, Editor. 2008, Woodhead Publishing. p. 426-460.

[41] Scollan, N.D., et al., Manipulating the fatty acid composition of muscle and adipose tissue in beef cattle. British Journal of Nutrition, 2001. 85(1): p. 115-124.

[42] Kanner, J., Oxidative Processes in Meat and Meat-Products - Quality Implications. Meat Science, 1994. 36(1-2): p. 169-189.

[43] Khayat, A. and D. Schwall, LIPID OXIDATION IN SEAFOOD. Food Technology, 1983. 37(7): p. 130-140.

[44] Sun, Q., et al., Aldehyde reactivity with 2-thiobarbituric acid and TBARS in freezedried beef during accelerated storage. Meat Science, 2001. 57(1): p. 55-60.

[45] Olsen, E., et al., Analysis of early lipid oxidation in smoked, comminuted pork or poultry sausages with spices. Journal of Agricultural and Food Chemistry, 2005. 53(19): p. 7448-7457.

[46] Varlet, V., C. Prost, and T. Serot, Volatile aldehydes in smoked fish: Analysis methods, occurence and mechanisms of formation. Food Chemistry, 2007. 105(4): p. 1536-1556.

[47] Gardner, H.W., in Xenobiotics in Foods and Feeds, J.M. Finley and D.E. Schwass, Editors. 1983, Am. Chem. Soc.: Washington D.C. p. 63-84.

[48] Frank, J., Dietary phenolic compounds and vitamin e bioavailability : model studies in rats and humans., in Acta Universitatis Agriculturae Suecia, Agraria, 446,. 2004, Swedish Univerisity of Agriculture, Department of Food Science: Uppsala, Sweden.

[49] Sanchez-Escalante, A., et al., The effects of ascorbic acid, taurine, carnosine and rosemary powder on colour and lipid stability of beef patties packaged in modified atmosphere. Meat Science, 2001. 58(4): p. 421-429.

[50] Amarowicz, R., Squalene: A natural antioxidant? European Journal of Lipid Science and Technology, 2009. 111(5): p. 411-412.

[51] Bosku, D., Olive oil, in Mediterranean diets, A.P. Simopoulos and F. Visioli, Editors. 2000, Karger: Basel, Freiburg, Paris, London, New York, New Delhi, Bangkok, Singapore, Tokyo, Sydney. p. 56-77. 
[52] He, H.P., et al., Extraction and purification of squalene from Amaranthus grain. Journal of Agricultural and Food Chemistry, 2002. 50(2): p. 368-372.

[53] Knoblich, M., B. Anderson, and D. Latshaw, Analyses of tomato peel and seed byproducts and their use as a source of carotenoids. Journal of the Science of Food and Agriculture, 2005. 85(7): p. 1166-1170.

[54] Benítez, V., et al., Characterization of Industrial Onion Wastes (Allium cepa L.): Dietary Fibre and Bioactive Compounds. Plant Foods for Human Nutrition, 2011. 66(1): p. $48-57$.

[55] O'Grady, M.N., et al., An assessment of dietary supplementation with tea catechins and rosemary extract on the quality of fresh beef. Meat Science, 2006. 73(1): p. 132-143.

[56] Kalogeropoulos, N., et al., Nutritional evaluation and bioactive microconstituents (carotenoids, tocopherols, sterols and squalene) of raw and roasted chicken fed on DHA-rich microalgae. Food Research International, 2010. 43(8): p. 2006-2013.

[57] Gülçin, I., et al., Determination of antioxidant activity of lichen Cetraria islandica (L) Ach. Journal of Ethnopharmacology, 2002. 79(3): p. 325-329.

[58] Larrain, R.E., et al., Color changes and lipid oxidation in pork products made from pigs fed with cranberry juice powder. Journal of Muscle Foods, 2008. 19(1): p. 17-33.

[59] Hilton, J.W., THE Interaction of vitamins, minerals and diet composition in the diet of fish. Aquaculture, 1989. 79(1-4): p. 223-244.

[60] Hamre, K., et al., Antioxidant vitamins, minerals and lipid levels in diets for Atlantic salmon (Salmo salar, L.): effects on growth performance and fillet quality. Aquaculture Nutrition, 2004. 10(2): p. 113-123.

[61] Palace, V.P. and J. Werner, Vitamins A and E in the maternal diet influence egg quality and early life stage development in fish: a review. 2006: p. 41-57.

[62] Shiau, S.-Y. and C.-Y. Hsu, Vitamin E sparing effect by dietary vitamin C in juvenile hybrid tilapia, Oreochromis niloticus $\diamond$ O. aureus. Aquaculture, 2002. 210(1-4): p. 335-342.

[63] Norouzitallab, P., et al., Comparing the efficacy of dietary alpha-tocopherol with that of dl-alpha-tocopheryl acetate, both either alone or in combination with ascorbic acid, on growth and stress resistance of angelfish, Pterophylum scalare, juveniles. Aquaculture International, 2009. 17(3): p. 207-216.

[64] Hamre, K., et al., Vitamins C and E interact in juvenile Atlantic salmon (Salmo salar, L). Free Radical Biology and Medicine, 1997. 22(1-2): p. 137-149.

[65] Rulıšek, L.r. and J. Vondrášek, Coordination geometries of selected transition metal ions (Co2+, $\mathrm{Ni2}+, \mathrm{Cu} 2+, \mathrm{Zn} 2+, \mathrm{Cd} 2+$, and $\mathrm{Hg} 2+)$ in metalloproteins. Journal of Inorganic Biochemistry, 1998. 71(3-4): p. 115-127. 
[66] Lauritzsen, K., G. Martinsen, and R.L. Olsen, Copper induced lipid oxidation during salting of COD (Gadus morhua L.). Journal of Food Lipids, 1999. 6(4): p. 299-315.

[67] Rhee, K.S. and Y.A. Ziprin, Pro-oxidative effects of $\mathrm{NaCl}$ in microbial growth-controlled and uncontrolled beef and chicken. Meat Science, 2001. 57(1): p. 105-112.

[68] Nawar, W.W., Chemical changes in lipids produced by thermal processing. Journal of Chemical Education, 1984. 61(4): p. 299-302.

[69] Pearson, A.M. and T.A. Gillett, Processed Meats. 1996, New York: Chapman \& Hall.

[70] Chizzolini, R., E. Novelli, and E. Zanardi, Oxidation in traditional Mediterranean meat products. Meat Science, 1998. 49: p. S87-S99.

[71] Gray, J.I. and A.M. Pearson, Rancidity and warmed-over flavor. Advanced Meat Research, 1987. 3: p. 221-269.

[72] Gill, C.O., Extending the storage life of raw chilled meats. Meat Science, 1996. 43(Supplement 1): p. 99-109.

[73] Garcia-Soto, B., et al., Preservative effect of an organic acid-icing system on chilled fish lipids. European Journal of Lipid Science and Technology, 2011. 113(4): p. 487-496.

[74] Quitral, V., et al., Chemical changes during the chilled storage of Chilean jack mackerel (Trachurus murphyi): Effect of a plant-extract icing system. Lwt-Food Science and Technology, 2009. 42(8): p. 1450-1454.

[75] Kaale, L.D., et al., Superchilling of food: A review. Journal of Food Engineering, 2011. 107(2): p. 141-146.

[76] Rahelić, S., S. Puač, and A.H. Gawwad, Structure of beef Longissimus dorsi muscle frozen at various temperatures: Part 1 -histological changes in muscle frozen at -10 , $-22,-33,-78,-115$ and $-196^{\circ} \mathrm{C}$. Meat Science, 1985. 14(2): p. 63-72.

[77] Deer Industry New Zealand. Venison, Shelf Life and Storage. 2012; Available from: http://www.nzgib.org.nz/n95.html.

[78] Ando, M., et al., Effect of Super Chilling Storage on Maintenance of Freshness of Kuruma Prawn. Food Science and Technology Research, 2004. 10(1): p. 25-31.

[79] Duun, A.S. and T. Rustad, Quality changes during superchilled storage of cod (Gadus morhua) fillets. Food Chemistry, 2007. 105(3): p. 1067-1075.

[80] Duun, A.S. and T. Rustad, Quality of superchilled vacuum packed Atlantic salmon (Salmo salar) fillets stored at -1.4 and $-3.6^{\circ} \mathrm{C}$. Food Chemistry, 2008. 106(1): p. 122-131.

[81] Jeremiah, L.E., Effect of frozen storage and protective wrap upon the cooking losses, palability, and rancidity of fresh and cured pork cuts. Journal of Food Science, 1980. 45(1-2): p. 187-196. 
[82] Miller, A.J., S.A. Ackerman, and S.A. Paumbo, Effects of frozen storage on functionality of meat for processing. Journal of Food Science, 1980. 45(5-6): p. 1466-1471.

[83] Leygonie, C., T.J. Britz, and L.C. Hoffman, Impact of freezing and thawing on the quality of meat: Review. Meat Science, 2012. 91(2): p. 93-98.

[84] Estevez, M., Protein carbonyls in meat systems: A review. Meat Science, 2011. 89(3): p. 259-279.

[85] Hernandez, P., J.L. Navarro, and F. Toldra, Effect of frozen storage on lipids and lipolytic activities in the longissimus dorsi muscle of the pig. Zeitschrift für Lebensmitteluntersuchung und -Forschung A, 1999. 208(2): p. 110-115.

[86] Li, B. and D.-W. Sun, Novel methods for rapid freezing and thawing of foods - a review. Journal of Food Engineering, 2002. 54(3): p. 175-182.

[87] Chevalier, D., et al., Comparison Of Air-blast And Pressure Shift Freezing On Norway Lobster Quality. Journal of Food Science, 2000. 65(2): p. 329-333.

[88] Gray, J.I. and A.M. Pearson, Cured Meat Flavor, in Advances in Food Research, C.O. Chichester, E.M. Mrak, and B.S. Schweigert, Editors. 1984, Academic Press, INC. p. $1-86$.

[89] Kanner, J., S. Harel, and R. Jaffe, LIPID-PEROXIDATION OF MUSCLE FOOD AS AFFECTED BY NACL. Journal of Agricultural and Food Chemistry, 1991. 39(6): p. 1017-1021.

[90] Morrissey, P.A. and J.Z. Tichivangana, The antioxidant activities of nitrite and nitrosylmyoglobin in cooked meats. Meat Science, 1985. 14: p. 175-190.

[91] Andersen, E., M.L. Andersen, and C.P. Baron, Characterization of oxidative changes in salted herring (Clupea harengus) during ripening. Journal of Agricultural and Food Chemistry, 2007. 55(23): p. 9545-9553.

[92] Goulas, A.E. and M.G. Kontominas, Effect of salting and smoking-method on the keeping quality of chub mackerel (Scomber japonicus): biochemical and sensory attributes. Food Chemistry, 2005. 93(3): p. 511-520.

[93] Park, J.N., et al., Partial replacement of $\mathrm{NaCl}$ by $\mathrm{KCl}$ in salted mackerel (Scomber japonicus) fillet products: effect on sensory acceptance and lipid oxidation. International Journal of Food Science and Technology, 2009. 44(8): p. 1572-1578.

[94] Lauritzsen, K. and R.L. Olsen, Effects of antioxidants on copper induced lipid oxidation during salting of cod (Gadus morhua L.). Journal of Food Lipids, 2004. 11(2): p. 105-122.

[95] Vestergaard, C.S. and G. Parolari, Lipid and cholesterol oxidation products in drycured ham. Meat Sci, 1999. 52(4): p. 397-401.

[96] Pastorelli, G., et al., Influence of dietary fat, on fatty acid composition and sensory properties of dry-cured Parma ham. Meat Science, 2003. 65(1): p. 571-580. 
[97] Sampels, S., J. Pickova, and E. Wiklund, Fatty acids, antioxidants and oxidation stability of processed reindeer meat. Meat Science, 2004. 67(3): p. 523-532.

[98] Mottram, D.S., Flavour formation in meat and meat products: a review. Food Chemistry, 1998. 62(4): p. 415-424.

[99] Coutron-Gambotti, C. and G. Gandemer, Lipolysis and oxidation in subcutaneous adipose tissue during dry-cured ham processing. Food Chemistry, 1999. 64(1): p. 95-101.

[100] Bosi, P., et al., Effects of dietary high-oleic acid sunflower oil, copper and vitamin E levels on the fatty acid composition and the quality of dry cured Parma ham. Meat Science, 2000. 54(2): p. 119-126.

[101] Jonsdottir, R., et al., Flavor and Quality Characteristics of Salted and Desalted Cod (Gadus morhua) Produced by Different Salting Methods. Journal of Agricultural and Food Chemistry, 2011. 59(8): p. 3893-3904.

[102] Lauritzsen, K., et al., Effects of calcium, magnesium and $\mathrm{pH}$ during salt curing of cod (Gadus morhua L). Journal of the Science of Food and Agriculture, 2004. 84(7): p. 683-692.

[103] Hwang, C.-C., et al., Effect of salt concentrations and drying methods on the quality and formation of histamine in dried milkfish (Chanos chanos). Food Chemistry, 2012. 135(2): p. 839-844.

[104] Gwak, H.J. and J.B. Eun, Changes in the chemical characteristics of Gulbi, salted and dried yellow corvenia, during drying at different temperatures. Journal of Aquatic Food Product Technology, 2010. 19(3-4): p. 274-283.

[105] Jónsdóttir, R., et al., Volatile compounds suitable for rapid detection as quality indicators of cold smoked salmon (Salmo salar). Food Chemistry, 2008. 109(1): p. 184-195.

[106] Forsberg, N.D., et al., Effect of native American fish smoking methods on dietary exposure to polycyclic aromatic hydrocarbons and possible risks to human health. Journal of Agricultural and Food Chemistry, 2012. 60(27): p. 6899-6906.

[107] Coronado, S.A., et al., Effect of dietary vitamin E, fishmeal and wood and liquid smoke on the oxidative stability of bacon during 16 weeks' frozen storage. Meat Science, 2002. 62(1): p. 51-60.

[108] Gonulalan, Z., A. Kose, and H. Yetim, Effects of liquid smoke on quality characteristics of Turkish standard smoked beef tongue. Meat Science, 2004. 66(1): p. 165-170.

[109] Espe, M., et al., Atlantic salmon (Salmo salar, L) as raw material for the smoking industry. II: Effect of different smoking methods on losses of nutrients and on the oxidation of lipids. Food Chemistry, 2002. 77(1): p. 41-46.

[110] Torri, L., B. Baroni, and M.R. Baroni, Modified atmosphere. 2009, Food Packages Free Press. 
[111] Ucak, I., Y. Ozogul, and M. Durmus, The effects of rosemary extract combination with vacuum packing on the quality changes of Atlantic mackerel fish burgers. International Journal of Food Science and Technology, 2011. 46(6): p. 1157-1163.

[112] Fernandez-Espla, M.D. and E. Oneill, Lipid Oxidation in Rabbit Meat under Different Storage- Conditions. Journal of Food Science, 1993. 58(6): p. 1262-1264.

[113] Jo, C., J.I. Lee, and D.U. Ahn, Lipid oxidation, color changes and volatiles production in irradiated pork sausage with different fat content and packaging during storage. Meat Science, 1999. 51(4): p. 355-361.

[114] Hampson, J.W., et al., Effect of low dose gamma radiation on lipids in five different meats. Meat Science, 1996. 42(3): p. 271-276.

[115] Sant'Ana, L.S. and J. Mancini-Filho, Influence of the addition of antioxidants in vivo on the fatty acid composition of fish fillets. Food Chemistry, 2000. 68(2): p. 175-178.

[116] Naseri, M., et al., Effects of different filling media on the oxidation and lipid quality of canned silver carp (Hypophthalmichthys molitrix). International Journal of Food Science and Technology, 2011. 46(6): p. 1149-1156.

[117] Medina, I., et al., Effect of Packing Media on the Oxidation of Canned Tuna Lipids. Antioxidant Effectiveness of Extra Virgin Olive Oil. Journal of Agricultural and Food Chemistry, 1998. 46(3): p. 1150-1157.

[118] Abdullah, B.M., Properties of five canned luncheon meat formulations as affected by quality of raw materials. International Journal of Food Science and Technology, 2007. 42(1): p. 30-35.

[119] Echarte, M., et al., Evaluation of the nutritional aspects and cholesterol oxidation products of pork liver and fish pates. Food Chemistry, 2004. 86(1): p. 47-53.

[120] Ferreira, E.L., et al., Natural Antioxidant from Yerba Mate (Ilex paraguariensis St. Hil.) Prevents Hamburger Peroxidation. Brazilian Archives of Biology and Technology, 2011. 54(4): p. 803-809.

[121] Sanjuas-Rey, M., et al., Effect of oregano and thyme essential oils on the microbiological and chemical quality of refrigerated (4 degrees $\mathrm{C}$ ) ready-to-eat squid rings. International Journal of Food Science and Technology, 2012. 47(7): p. 1439-1447.

[122] El-Alim, S.S.L.A., et al., Culinary herbs inhibit lipid oxidation in raw and cooked minced meat patties during storage. Journal of the Science of Food and Agriculture, 1999. 79(2): p. 277-285.

[123] Ahn, D.U., et al., Packaging and irradiation effects on lipid oxidation and volatiles in pork patties. J Food Sci, 1998. 63(1): p. 15-9.

[124] Aguirrezabal, M.M., et al., The effect of paprika, garlic and salt on rancidity in dry sausages. Meat Science, 2000. 54(1): p. 77-81. 
[125] Nassu, R.T., et al., Oxidative stability of fermented goat meat sausage with different levels of natural antioxidant. Meat Science, 2003. 63(1): p. 43-49.

[126] Ansorena, D., et al., Addition of Palatase M (Lipase from Rhizomucor miehei) to dry fermented sausages: Effect over lipolysis and study of the further oxidation process by GC-MS. Journal of Agricultural and Food Chemistry, 1998. 46(8): p. 3244-3248.

[127] Halliwell, B. and J.M.C. Cuttteridge, Free radicals in biology and medicine. 2nd edition ed. 1988, Oxford, UK: Claredon Press.

[128] Robards, K., et al., Phenolic compounds and their role in oxidative processes in fruits. Food Chemistry, 1999. 66(4): p. 401-436.

[129] Rice-Evans, C., N. Miller, and G. Paganga, Antioxidant properties of phenolic compounds. Trends in Plant Science, 1997. 2(4): p. 152-159.

[130] Bhale, S.D., et al., Oregano and rosemary extracts inhibit oxidation of long-chain n-3 fatty acids in menhaden oil. Journal of Food Science, 2007. 72: p. C504-C508.

[131] Afonso, M.d.S. and L.S. Sant'ana, Effects of pretreatment with rosemary (Rosmarinus officinalis L.) in the prevention of lipid oxidation in salted tilapia fillets. Journal of Food Quality, 2008. 31(5): p. 586-595.

[132] Tanabe, H., M. Yoshida, and N. Tomita, Comparison of the antioxidant activities of 22 commonly used culinary herbs and spices on the lipid oxidation of pork meat. Animal Science Journal, 2002. 73: p. 389-393.

[133] Abuja, P.M., M. Murkovic, and W. Pfannhauser, Antioxidant and prooxidant activities of elderberry (Sambucus nigra) extract in low-density lipoprotein oxidation. Journal of Agricultural and Food Chemistry, 1998. 46(10): p. 4091-4096.

[134] Hakkinen, S.H., et al., Content of the flavonols quercetin, myricetin, and kaempferol in 25 edible berries. Journal of Agricultural and Food Chemistry, 1999. 47(6): p. 2274-2279.

[135] Mielnik, M.B., et al., Grape seed extract as antioxidant in cooked, cold stored turkey meat. Lwt-Food Science and Technology, 2006. 39(3): p. 191-198.

[136] Pazos, M., et al., Activity of grape polyphenols as inhibitors of the oxidation of fish lipids and frozen fish muscle. Food Chemistry, 2005. 92(3): p. 547-557.

[137] Lee, C.H., J.D. Reed, and M.P. Richards, Ability of various polyphenolic classes from cranberry to inhibit lipid oxidation in mechanically separated turkey and cooked ground pork. Journal of Muscle Foods, 2006. 17(3): p. 248-266.

[138] Sánchez-Alonso, I., et al., Effect of grape antioxidant dietary fibre on the prevention of lipid oxidation in minced fish: Evaluation by different methodologies. Food Chemistry, 2007. 101(1): p. 372-378. 
[139] Tang, S., et al., Anti-oxidant activity of added tea catechins on lipid oxidation of raw minced red meat, poultry and fish muscle. International Journal of Food Science \& Technology, 2001. 36(6): p. 685-692.

[140] Alghazeer, R., S. Saeed, and N.K. Howell, Aldehyde formation in frozen mackerel (Scomber scombrus) in the presence and absence of instant green tea. Food Chemistry, 2008. 108: p. 801-810.

[141] Kanatt, S.R., R. Chander, and A. Sharma, Chitosan glucose complex - A novel food preservative. Food Chemistry, 2008. 106(2): p. 521-528.

[142] Shao, D., et al., Study of Optimal Extraction Conditions for Achieving High Yield and Antioxidant Activity of Tomato Seed Oil. Journal of Food Science, 2012. 77(8): p. E202-E208.

[143] Kalogeropoulos, N., et al., Bioactive phytochemicals in industrial tomatoes and their processing byproducts. LWT - Food Science and Technology, 2012. 49(2): p. 213-216.

[144] Pazos, M., et al., Physicochemical properties of natural phenolics from grapes and olive oil byproducts and their antioxidant activity in frozen horse mackerel fillets. Journal of Agricultural and Food Chemistry, 2006. 54(2): p. 366-373.

[145] Ganesan, P., C.S. Kumar, and N. Bhaskar, Antioxidant properties of methanol extract and its solvent fractions obtained from selected Indian red seaweeds. Bioresource Technology, 2008. 99(8): p. 2717-2723.

[146] Skibsted, L.H., Carotenoids in Antioxidant Networks. Colorants or Radical Scavengers. Journal of Agricultural and Food Chemistry, 2012. 60(10): p. 2409-2417.

[147] Bohm, F., et al., Carotenoids enhance vitamin E antioxidant efficiency. Journal of the American Chemical Society, 1997. 119(3): p. 621-622.

[148] Psomiadou, E. and M. Tsimidou, Stability of Virgin Olive Oil. 2. Photo-oxidation Studies. Journal of Agricultur and Food Chemistry, 2002. 50(4): p. 722-727.

[149] Jensen, C., et al., Effect of dietary levels of fat, alpha-tocopherol and astaxanthin on colour and lipid oxidation during storage of frozen rainbow trout (Oncorhynchus mykiss) and during chill storage of smoked trout. Zeitschrift Fur Lebensmittel-Untersuchung Und-Forschung a-Food Research and Technology, 1998. 207(3): p. 189-196.

[150] Heinonen, M.I., Antioxidant activity and antimicrobial effect of berry phenolics - a Finnish perspective. Molecular Nutrition \& Food Research, 2007. 51(6): p. 684-691.

[151] Hussein, G., et al., Astaxanthin, a carotenoid with potential in human health and nutrition. Journal of Natural Products, 2006. 69(3): p. 443-449.

[152] Chirumbolo, S., Plant phytochemicals as new potential drugs for immune disorders and cancer therapy: really a promising path? Journal of the Science of Food and Agriculture, 2012. 92(8): p. 1573-1577. 
[153] Narotzki, B., et al., Green tea: A promising natural product in oral health. Archives of Oral Biology, 2012. 57(5): p. 429-435.

[154] Howell, A.B., Bioactive compounds in cranberries and their role in prevention of urinary tract infections. Molecular Nutrition \& Food Research, 2007. 51(6): p. 732-737.

[155] Céspedes, C.L., et al., Antioxidant and cardioprotective activities of phenolic extracts from fruits of Chilean blackberry Aristotelia chilensis (Elaeocarpaceae), Maqui. Food Chemistry, 2008. 107(2): p. 820-829.

[156] Joseph, J.A., B. Shukitt-Hale, and L.M. Willis, Grape Juice, Berries, and Walnuts Affect Brain Aging and Behavior. Journal of Nutrition, 2009. 139(9): p. 1813S-1817S.

[157] Lin, Y.T., et al., Inhibition of Helicobacter pylori and Associated Urease by Oregano and Cranberry Phytochemical Synergies. Appl. Environ. Microbiol., 2005. 71(12): p. 8558-8564.

[158] Lin, Y.T., R.G. Labbe, and K. Shetty, Inhibition of Listeria monocytogenes in fish and meat systems by use of oregano and cranberry phytochemical synergies. Applied and Environmental Microbiology, 2004. 70(9): p. 5672-5678.

[159] Arihara, K., Strategies for designing novel functional meat products. Meat Science, 2006. 74(1): p. 219-229. 